\title{
Testing and Refinement of e-Learning Modules on Metacognition and Moti-
} vation

Dr. Michele Miller, Michigan Technological University

Dr. Michele Miller is an associate professor of Mechanical Engineering at Michigan Technological University. She teaches classes on manufacturing and does research in engineering education with particular interest in hands-on ability, lifelong learning, and project-based learning.

Dr. Sheryl A. Sorby, Ohio State University

Miss Apurva Anil Kambale, Michigan Technological University

Megan Farrish 


\section{Testing and Refinement of e-Learning Modules on Metacognition and Motivation}

\section{Introduction}

Engineering graduates of today must be prepared for a lifetime of learning and adaptation. Thus, one of the goals of engineering education is to create independent, lifelong learners. This project is developing e-learning modules in support of that goal. The modules are designed to teach undergraduate engineering students about metacognition and motivation as well as strategies to improve learning. Both modules begin with an instrument (learning style inventory or motivation questionnaire), then a tutorial that gives students a first hand experience of the influence of learning style or motivation, then questions of understanding, then a tutorial about learning style or motivation strategies, and finishing with reflection questions and an evaluation of the module. The learning style module creates the "first hand experience" by asking students to learn material that is presented in different learning styles. The motivation module manipulates task value and control beliefs in its presentation of new material to learn.

The modules have been implemented in two mechanical engineering classes: a sophomore level manufacturing class and a junior level design processes class. To test the effectiveness of the modules, we compare results from a lifelong learning readiness instrument.

\section{Data Collection}

Figure 1 shows what type of data has been collected over four semesters. Student participants took two computer modules: a learning styles module and a motivation module. The SelfDirected Learning Readiness Survey (SDLRS) ${ }^{1}$ was taken pre and post as a measure of the impact of the modules. In the first semester of data collection-Spring 2012 - many participants failed to complete both the pre and post SDLRS. Thus, for subsequent semesters, participants have been randomly assigned to take the SDLRS either before or after taking the modules.

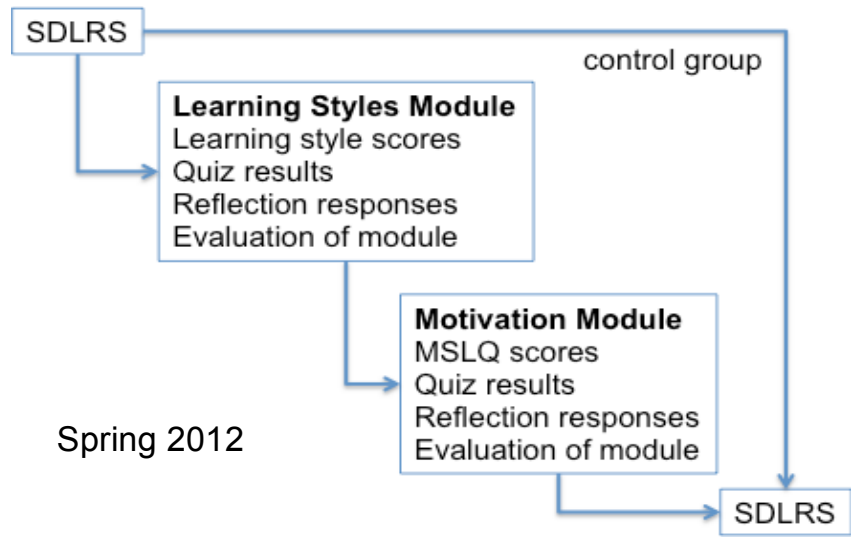

Fall 2012, Spring 2013, Fall 2013

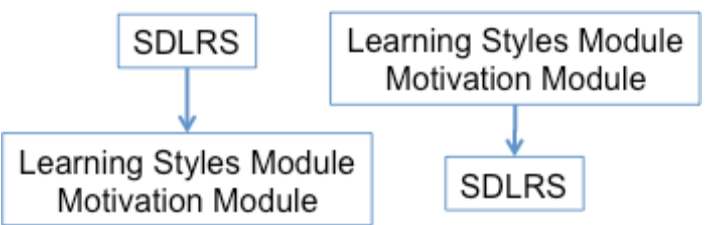

Figure 1: Data collection scheme in $2^{\text {nd }}$ year manufacturing class and $3^{\text {rd }}$ year design processes class for the last four semesters 


\section{Results}

The SDLRS can identify scores for four factors: viewing learning as a tool for life, selfconfidence, responsibility for learning, and curiosity. ${ }^{2}$ Figure 2 shows average values for these four factors from the pre and post-tests. Two factors show statistically significant increases from pre to post: Self-Confidence and Responsibility.

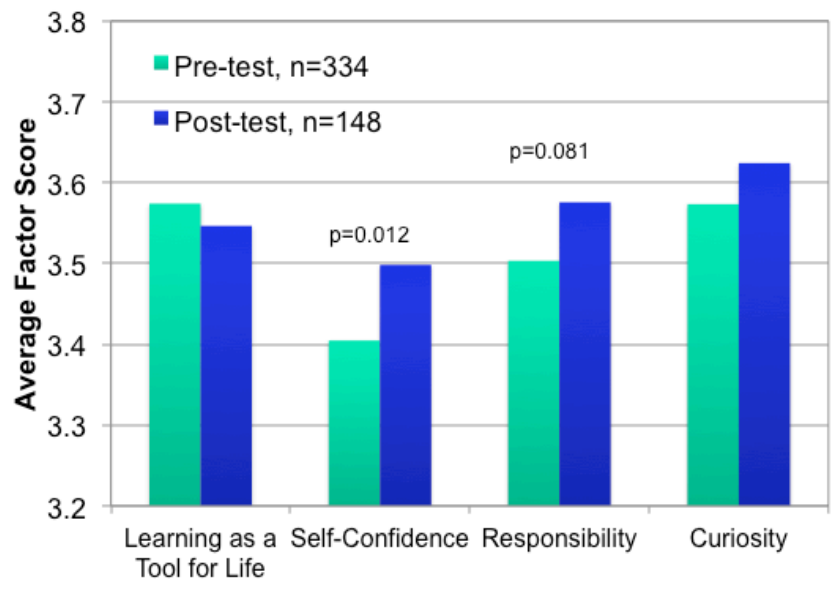

Figure 2: Pre and post-test results for lifelong learning readiness factors

\section{Module Re-Design}

Based on student evaluations of the modules, we recently made significant modifications to both modules. For example, students reported they were already familiar with their preferred learning style based on the categories of visual, auditory, tactile, and kinesthetic. In response, we replaced the Barsch learning style inventory ${ }^{3}$ with the Felder-Silverman one ${ }^{4}$ to expose students to additional less familiar aspects of learning styles. This index classifies learning styles along four dimensions: visual vs. verbal, sensing vs. intuitive, active vs. reflective, and global vs. sequential. Also, in the first version, students found the tutorial materials on topics such as osmosis, mitosis, and Punnett squares to be boring. The second version includes topics that students will find more relevant to their lives, such as food and nutrition. Figures 3 and 4 show screenshots of the revised learning style module. The visual-verbal dimension is straightforward to realize in a computer module. However, other dimensions require more imagination. For the globalsequential dimension, we target the global learning style by using hyperlinks so that participants can jump back and forth between pages. For the sequential learning style, the module presents the pages in sequential order. 


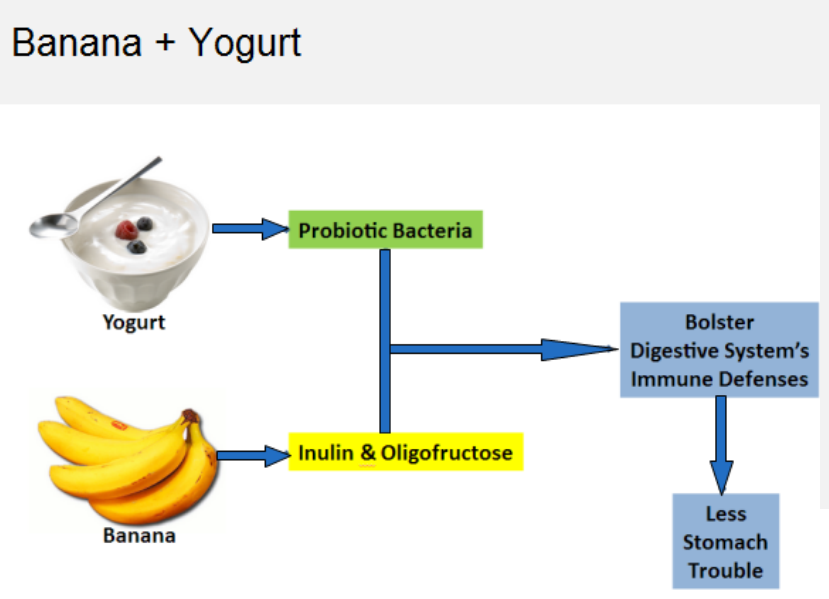

\section{Red Wine + Almonds}

This magic food pairing of red wine and almonds will help you to get a natural combo that keeps your heart happy.

The antioxidant resveratrol in red wine and an almond's naturally high levels of vitamin $E$ work together to thin the blood and improve blood vessel health which leads to a healthier heart.

And here is a tip for this food pairing: look for organic wine, since conventional versions have been found to harbor pesticide residues

Figure 3: Screenshots from the visual (left) and verbal (right) portions of the revised learning styles module

\section{METACOGNITION}

\section{Vendor-Managed Inventory}

So what exactly is VMI? How can it help?

\section{Vendor-Managed Inventory}

An inventory management method

Benefits

Challenges

Conclusion
VMI (Vendor Managed Inventory) is a process where the upstream generates orders for the downstream based on demand information sent by the downstream This new inventory process will get rid of the backlog and excess stock problems

illustrated in the root beer exercise.

\section{Step 1: Product Activity Record}

The downstream report the product sales information to the upstream

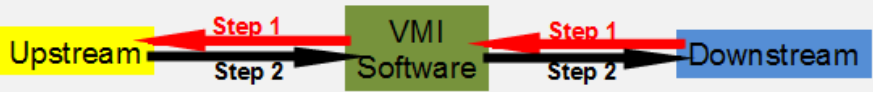

Step 2: Information Feedback

The upstream inform the downstream what inventories to expect

Figure 4: Screenshots from the global (left) and sequential (right) portions of the revised learning styles module

The motivation module manipulates two aspects of motivation: task value and control beliefs. The goal of the module is to have students experience different motivation levels while learning a new topic. Common student comments about the module were that it was boring and too long. In response, we changed the module topics and simplified the module. For the task value portion in the revised module, the two topics are black holes and food swaps. Figure 5 shows two screenshots from this portion. 


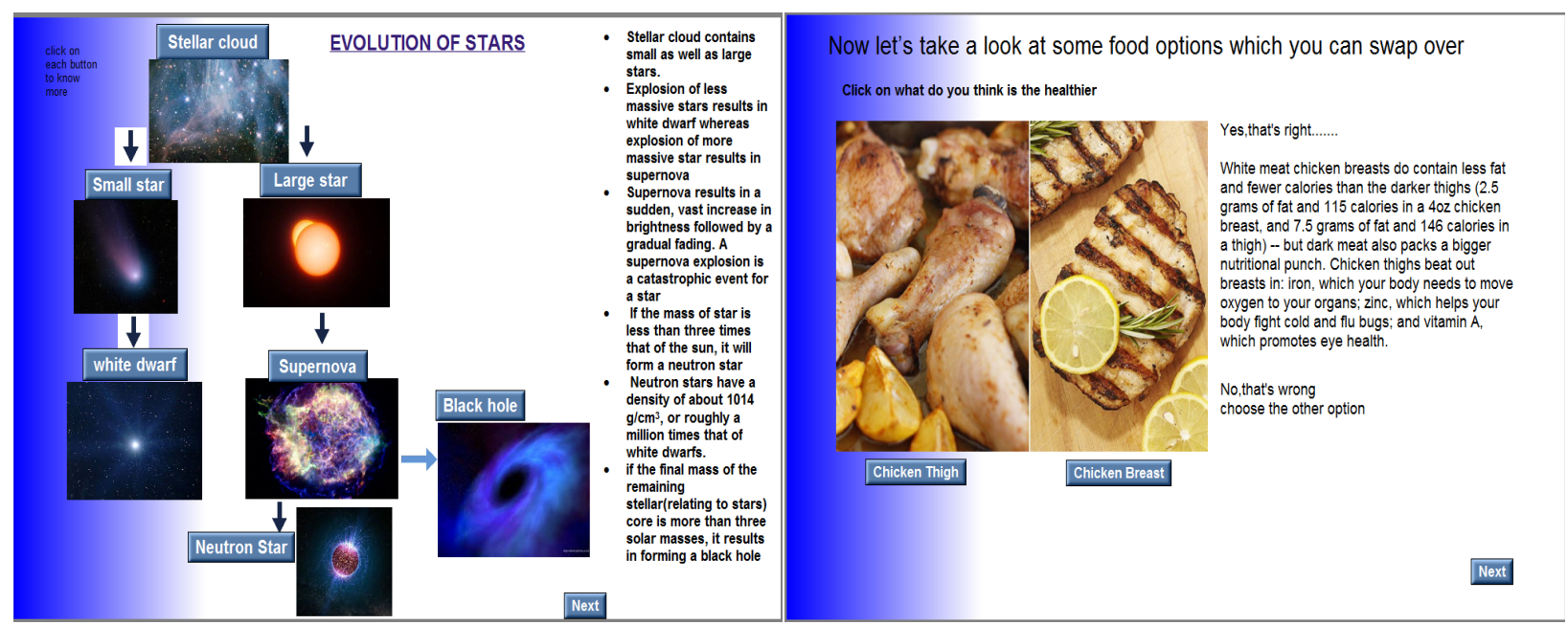

Figure 5: Screenshots from the task value portion of the motivation module

For the control beliefs portion, the two topics are seismology and nuclear fission. Figure 6 shows screenshots from this portion of the module.
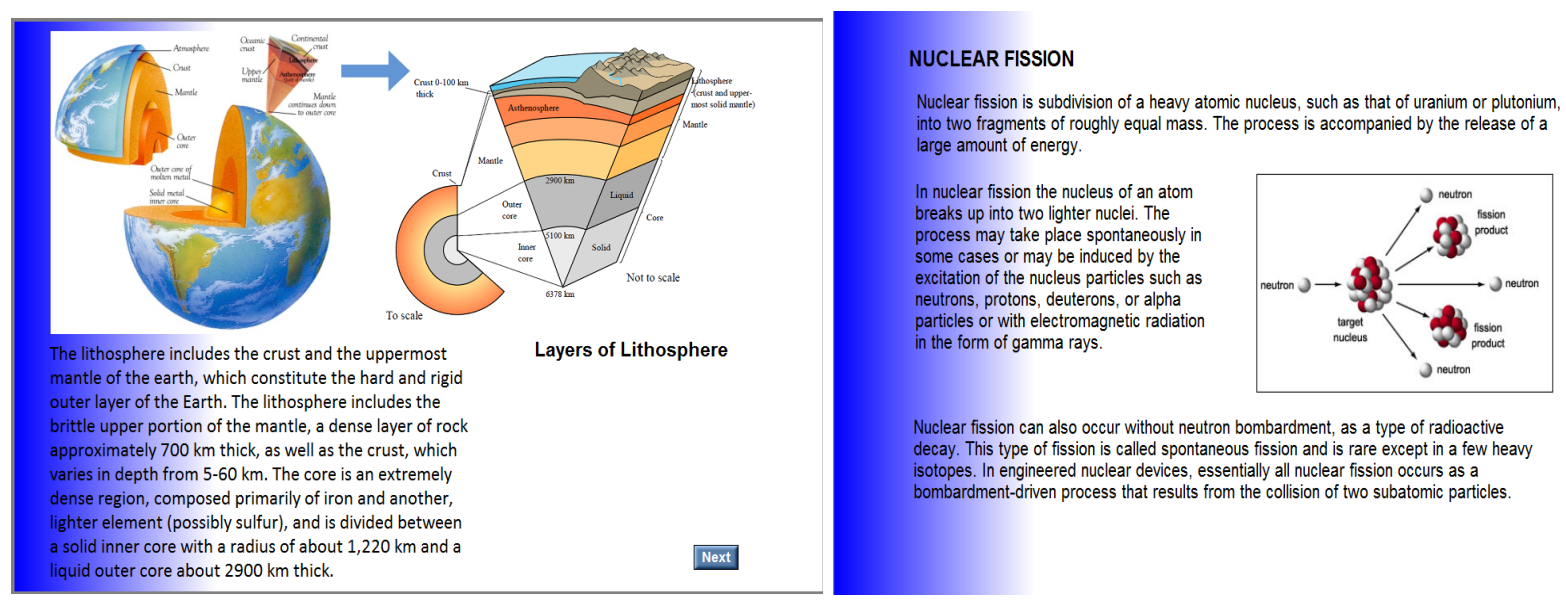

Figure 6: Screenshots from the control beliefs portion of the motivation module

\section{Conclusions and Future Work}

This project has developed two computer modules for the purpose of teaching about learning styles and motivation. An understanding of these two aspects of learning will help students become more independent and effective lifelong learners. Based on four semesters of testing, the modules do have some effect on a lifelong learning readiness measure. Based on student feedback, both modules have undergone extensive revisions and will be further tested.

\section{Acknowledgment}

This material is based upon work supported by the National Science Foundation under grant number EEC-1024628. 


\section{References}

1. Guglielmino, L. M., Development of the self-directed learning readiness scale, Doctoral dissertation, University of Georgia, Dissertation Abstracts International, Vol. 38, No. 6467A, 1978.

2. Hoban J. D., Lawson S. R., Mazmanian P. E., Best A. M., and Seibel H. R., "The Self-Directed Learning Readiness Scale: a factor analysis study," Med Educ, Vol. 39, No. 4, pp. 370-379, 2005.

3. J. Barsch, Barsch Learning Style Inventory, New York: Academic Therapy Publications, 1996.

4. R. M. Felder and L. K. Silverman, "Learning and teaching styles in engineering education," Engr. Education, Vol. 78, No. 7, pp. 674-681, 1988. 